diseases. Direct retroperitoneal pelvic access seems interesting in children when low urinary tract malformations are concerned. We report a case of a 12-year-old boy with a blind ectopic ureter managed by pelvic retroperitoneoscopy. We describe the surgical technique, focusing on the difficulty in the pediatric population. Nevertheless, retroperitoneoscopy is an excellent alternate way to manage such ureteral malformations.

Key words: Retroperitoneoscopy - Ureteral ectopia Correspondence to: T. Petit

\section{Ectopic liver (choristoma) associated with the gallbladder encountered during laparoscopic cholecystectomy}

\author{
A. Sakarya, Y. Erhan, H. Aydede, E. Kara, Ö. Ilkgül, \\ C. Çiftdoğan \\ Department of General Surgery, Celal Bayar University, Manisa, \\ Turkey \\ Received: 20 December 2001/Accepted in final form: 17 January 2002/ \\ Online publication: 7 May 2002 \\ DOI: $10.1007 / \mathrm{s} 00464-001-4251-5$
}

\section{Abstract}

Ectopic liver has been but rarely described usually in the vicinity of liver such as on the gallbladder, hepatic ligaments, diaphragm, thoracic cavity, adrenal glands, pancreas, omentum, spleen, esophagus and umblical cord. A simple classification for anomalous liver tissues found on the wall of gallbladder is 1. Accessory liver lobe 2. Ectopic nodule 3. Aberrant microscopic tissue. Ectopic nodules of liver tissue attached to the gallbladder are completely detached from the liver and has been described by various names such as accessory lobe, ectopic liver, accessory liver and heterotopic liver but the specific pathological term for this entity is choristoma introduced by Albert in 1904 meaning displacement. Several possible mechanisms may explain ectopic liver at various sites such as the development of an accessory lobe of the liver with atrophy or regression of the original connection to the main liver or migration of pars hepatica to the rudiment of various organs. In this paper we present a case of ectopic liver or choristoma attached to the gallbladder encountered during an elective laparoscopic cholecystectomy which was successfully removed with the gallbladder.

Key words: Choristoma - Ectopic liver - Laparoscopic cholecystectomy

Correspondence to: A. Sakarya-238/2 sok. Selin Sitesi

A Blok No:3 D:7 Bornova 35040, zmir, Turkey

\section{Thoracoscopic treatment for spontaneous hemopneumothorax}

M. Miyazawa, T. Fujita, R. Misawa, T. Sakai, M. Toishi, H. Koyama, A. Hyougotani, Y. Haba, K. Kato, A. Muramatsu Department of Surgery, Kofu Municipal Hospital, 366 Masutsubo, Kofu 400-0832, Japan

Received: 19 December 2001/Accepted in final form: 25 February 2002/Online publication: 7 May 2002

DOI: $10.1007 / \mathrm{s} 00464-001-4182-1$

\begin{abstract}
Spontaneous hemopneumothorax is a rare clinical entity sometimes requiring an operation in the early stage. Two patients who underwent successful video-assisted thoracic surgery (VATS) for spontaneous hemopneumothorax are presented. In both cases, the bleeding point was clearly identified, and hemostasis was easily obtained by clipping the point and placing three access ports in the usual fashion. Furthermore, the evacuation of clotted blood and resection of bulla were performed with no difficulties. The postoperative courses were smooth, and no complications occurred, although the preoperative general condition in the second case was hemodynamically unstable. The advantages of VATS over conventional thoracotomy include less time required to access the pleural cavity, a better view, and more facilitated manipulation during surgery. Because spontaneous hemopneumothorax is a benign disease, VATS should be considered an initial treatment option in all patients with this condition, even those with active bleeding.
\end{abstract}

Key words: Spontaneous hemopneumothorax - Video assisted thoracic surgery

Correspondence to: M. Miyazawa

\section{Laparoscopic transgastric endoscopic retrograde cholangiopancreatography for benign common bile duct stricture after Roux-en-Y gastric bypass}

M. Peters, ${ }^{1}$ P. K. Papasavas, ${ }^{2}$ P. F. Caushaj, ${ }^{2}$ R. J. Kania, ${ }^{2}$ D. J. Gagné ${ }^{2}$

${ }^{1}$ Department of Surgery, Pinnacle Health Hospitals, 205 South Front Street, Harrisburg, PA 17104, USA

${ }^{2}$ Departments of Surgery and Gastroenterology, Temple University Clinical Campus at the Western Pennsylvania Hospital,

4800 Friendship Avenue, Pittsburgh, PA 15224, USA

Received: 11 December 2001/Accepted in final form: 7 February 2002/ Online publication: 7 May 2002

DOI: $10.1007 / \mathrm{s} 00464-001-4180-3$

\section{Abstract}

Access to the gastric remnant and duodenum is lost after laparoscopic Roux-en-Y gastric bypass for morbid obesity. Traditionally, a percutaneous transhepatic access to the common bile duct has been used to manage choledocholithiasis and duct strictures. We present a novel method of laparoscopic transgastric endoscopic retrograde cholangiopancreatography for managing a benign biliary stricture after a Roux-en-Y gastric bypass. Key words: Gastric bypass - ERCP — Bile duct stricture - Laparoscopic - Transgastric - Roux-en-Y Correspondence to: D. Gagné

\section{Radiation stricture of rectosigmoid treated with self-expanding metallic stent}

W. L. Law, H. K. Choi, K. W. Chu, H. M. Tung Department of Surgery, Queen Mary Hospital, University of Hong Kong Medical Centre, Porkulam Road, Hong Kong, China Received: 29 January 2002/Accepted in final form: 7 February 2002/ Online publication: 7 May 2002

DOI: $10.1007 / \mathrm{s} 00464-001-4113-1$ 